\title{
Influence of the Synthesis pH on the Properties and Activity of Sol-Gel $\mathrm{TiO}_{2}$ Photocatalysts
}

\author{
Javier Marugán, ${ }^{1}$ Paul Christensen, ${ }^{2}$ Terry Egerton, ${ }^{2}$ and Herry Purnama ${ }^{2}$ \\ ${ }^{1}$ Department of Chemical and Environmental Technology (ESCET), Universidad Rey Juan Carlos, C/ Tulipán s/n, \\ Móstoles 28933, Madrid, Spain \\ ${ }^{2}$ School of Chemical Engineering and Advanced Materials, University of Newcastle upon Tyne, Bedson Building, \\ Newcastle upon Tyne NE1 7RU, UK \\ Correspondence should be addressed to Javier Marugán, javier.marugan@urjc.es
}

Received 24 August 2007; Accepted 5 January 2008

Recommended by Russell Howe

The activity of titania photocatalysts is highly dependent on the synthesis procedure. This work reports a study of the correlation between the photocatalytic activity and the physicochemical and photoelectrochemical properties of sol-gel $\mathrm{TiO}_{2}$ powders and electrodes synthesized using different $\mathrm{pH}$ values and temperatures. The activity of the materials has been evaluated using the decolorization of Reactive Orange 16 (RO16) as model reaction. In contrast with the large number of studies reporting the influence of the temperature, our results point out that preparation $\mathrm{pH}$ has even more influence on the crystalline phases and the photocatalytic activity of $\mathrm{TiO}_{2}$ powders and photocurrents of the electrodes. However, the effects on the activity and the photocurrents recorded after immobilization on a conducting support do not vary accordingly. Consequently, our results indicate that the measurement of the photocurrent in an electrolyte media is not a good indicator of the photocatalytic activity of the unsupported system.

Copyright (C) 2008 Javier Marugán et al. This is an open access article distributed under the Creative Commons Attribution License, which permits unrestricted use, distribution, and reproduction in any medium, provided the original work is properly cited.

\section{INTRODUCTION}

The fundamentals of semiconductor photocatalysis and its application to the removal of chemical pollutants have been extensively reviewed [1-5]. However, commercialization of photocatalysis for water treatment has been hindered both by difficulties of postreaction catalyst recovery [6] and by low-quantum efficiencies [7], which means that large reactors are required for small-capacity plants. Consequently, although immobilized $\mathrm{TiO}_{2}$ has been shown to be less active than slurry systems, much effort has been devoted to the development of highly active fixed catalysts. One approach is to immobilize the $\mathrm{TiO}_{2}$ on a conducting support and apply a potential bias. This, simultaneously, addresses both problems [8].

The activity of titania powders and electrodes is highly dependent on the synthesis procedure $[9,10]$. A common way of synthesizing $\mathrm{TiO}_{2}$ electrodes is to coat conducting materials with titania sol-gel suspensions, as this procedure provides fine control of the physicochemical properties of the
$\mathrm{TiO}_{2}$ crystalline phase and hence of its photocatalytic activity [11]. The heat treatment temperature used to crystallize the titania has been shown to be critical in the activity of sol-gel coatings [12]. However, to the best of our knowledge, there are no reports about the influence of the synthesis $\mathrm{pH}$ or of the $\mathrm{pH}$ of coating suspensions on the activity and photoelectrochemical properties of the catalysts.

In this work we have studied the correlation between the photocatalytic activity and the physicochemical and photoelectrochemical properties of sol-gel $\mathrm{TiO}_{2}$ synthesized using two different $\mathrm{pH}$ routes. The activity of the materials has been evaluated using the decolorization of Reactive Orange 16 as model reaction.

\section{EXPERIMENTAL}

\subsection{Synthesis of the materials}

Titanium dioxide sols were prepared by hydrolysis and condensation of titanium tetraisopropoxide (TTIP) (97\%, 
Sigma Aldrich, Gillingham, UK) at different $\mathrm{pH}$ values, following a procedure based on that described by O'Regan et al. [13]. Powder photocatalysts were obtained from the colloidal suspensions by increasing the $\mathrm{pH}$ to 7 with sodium hydroxide and vacuum filtering through a $2.7 \mu \mathrm{m}$ paper filter (Whatman plc, Maidstone, UK). The filter cake was resuspended in deionized water three times to remove the ions from the solution until the filtrate conductivity fell below $200 \mu \mathrm{S} \cdot \mathrm{cm}^{-1}$, and finally was rinsed twice with 2-propanol to minimize particle agglomeration. The solids were dried at room temperature and then calcined at the desired temperature for two hours.

To prepare the electrodes, the titania colloidal suspension was first concentrated to $\mathrm{ca}$. $150 \mathrm{~g} \cdot \mathrm{L}^{-1}$, using a vacuum rotary evaporator, to increase the viscosity. Thin-film electrodes were fabricated by dropping suspension onto $1 \mathrm{~cm} \times 1 \mathrm{~cm}$ titanium plates (99.6\%, Goodfellow, Huntingdon, UK) and spinning at $2800 \mathrm{rpm}$ prior to calcination for 10 minutes at the desired temperature. The dropping, spinning, and heating sequence were repeated five times. The white coating was more apparent on the neutral $(\mathrm{pH} \mathrm{6.5)}$ plates than on the acid ( $\mathrm{pH} 1.5$ ) electrodes.

\subsection{Characterization techniques}

$\mathrm{X}$-ray diffractograms (XRD) were collected in the range $10<2 \theta<90^{\circ}$ in a Philips X'Pert diffractometer using nickelfiltered monochromatic $\mathrm{Cu} \mathrm{K} \alpha$ radiation. In all cases, only anatase and rutile crystalline phases were detected. To investigate the morphology of the $\mathrm{TiO}_{2}$ electrodes, scanning electron microscopy (SEM) micrographs were taken on a JEOL JSM5300LV working at an acceleration voltage of $25 \mathrm{kV}$ under environmental conditions, without conductive coating on the sample.

Diffuse reflectance spectra (DRS) of the small plate electrodes were recorded from $200-500 \mathrm{~nm}$ relative to a polytetrafluoroethylene reference with a Varian Cary 500 Scan U-VIS-NIR spectrophotometer equipped with an integrating sphere diffuse reflectance accessory. Reflectances were reported as the Kubelka-Munk function, F(R), whose value, for constant scattering, is proportional to the absorption.

Electrochemical characterization of the small plate electrodes was carried out by cyclic voltammetry, with a sweep rate of $100 \mathrm{mV} \mathrm{s}^{-1}$, using an Eco-Chemie $\mu$ Autolab Type II potentiostat. Potentials were quoted with respect to an $\mathrm{Ag} / \mathrm{AgCl}$ reference electrode and a $10 \mathrm{~cm}$ in diameter nickel gauze was employed as counter electrode. Photocurrents were recorded under illumination by two $36 \mathrm{~W}$ actinic UV lamps (Philips Lighting, Guildford, UK).

\subsection{Photoreactions procedure}

The photoreactor was a cylindrical concentric system with two axially located $8 \mathrm{~W}$ UV lamps (Sylvania: Light Bulbs Direct, Amersham, UK), two Pyrex glass walls containing the suspension of catalyst in the dye solution, and a sintered frit distributing the sparge oxygen. More details about the reactor can be found elsewhere [12]. The photocatalytic activity of the photocatalysts was evaluated using the decolorization

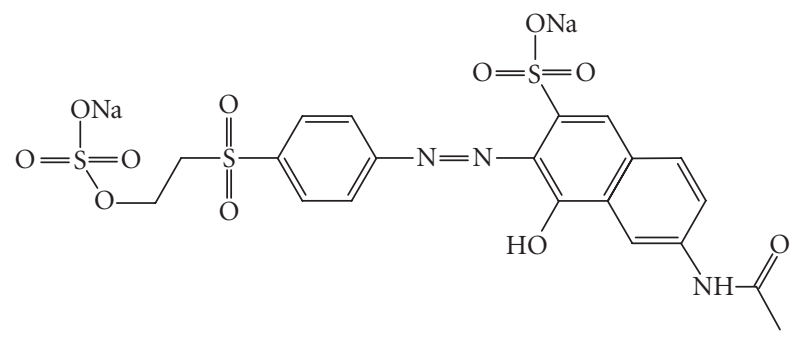

Scheme 1: Reactive Orange 16 (RO16).

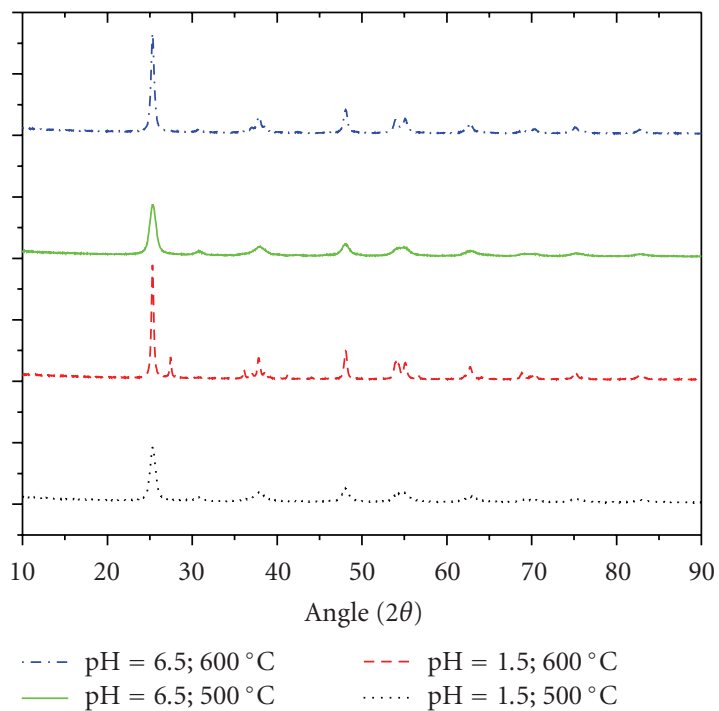

Figure 1: X-ray diffraction pattern of pure titania powder photocatalysts.

of the azo dye Reactive Orange 16 (RO16), represented in Scheme 1, as a model reaction. The initial concentration of dye was $0.05 \mathrm{mM}$. The $\mathrm{pH}$ obtained after dissolution of the dye in deionized water was used without further adjustment. The catalyst loading was $0.5 \mathrm{~g} \cdot \mathrm{L}^{-1}$ in all the experiments.

Prior to the start of the reaction, the dye solutions were equilibrated in the dark for 30 minutes in contact with the $\mathrm{TiO}_{2}$ material and the oxygen bubbles. After switching on the lamps, the evolution of the reaction was followed by colorimetric measurements $\left(\varepsilon_{493 \mathrm{~nm}}=23.45 \mathrm{~L} \cdot \mathrm{mmol}^{-1} \cdot \mathrm{cm}^{-1}\right)$ using a Shimadzu UV/vis spectrophotometer.

\section{RESULTS AND DISCUSSION}

\subsection{Characterization results}

The initial synthesis of the pure titania powder photocatalysts followed the original acidic procedure of O'Regan et al. [13], described above. The influence of the calcination temperature was investigated first. As shown in Figure 1, the diffraction line breadth demonstrates that the $\mathrm{TiO}_{2}$ existed as small crystallites of anatase after calcination at $500^{\circ} \mathrm{C}$ but that after calcination at $600^{\circ} \mathrm{C}$, these crystals grew substantially and transformed to rutile. 
TABLE 1: Synthesis conditions, crystallinity, and photocatalytic activity in terms of the first- order kinetic constant for RO16 decolorization of powder photocatalysts.

\begin{tabular}{|c|c|c|c|c|c|c|}
\hline Name & $\mathrm{pH}$ & Temp. $\left({ }^{\circ} \mathrm{C}\right)$ & Anatase (\%) & $\begin{array}{l}\text { XRD Data } \\
D_{\text {anat }}(\mathrm{nm})\end{array}$ & $S_{g}^{\dagger}\left(\mathrm{m}^{2} \mathrm{~g}^{-1}\right)$ & $k_{\mathrm{RO}}\left(\mathrm{h}^{-1}\right)$ \\
\hline $\mathrm{P}-\mathrm{TiO}_{2}-1$ & 1.5 & 500 & 100 & 14 & 110 & 0.22 \\
\hline $\mathrm{P}-\mathrm{TiO}_{2}-2$ & 1.5 & 600 & 89 & 42 & 37 & 0.32 \\
\hline $\mathrm{P}-\mathrm{TiO}_{2}-3$ & 6.5 & 500 & 100 & 12 & 128 & 0.38 \\
\hline $\mathrm{P}-\mathrm{TiO}_{2}-4$ & 6.5 & 600 & 100 & 24 & 64 & 1.09 \\
\hline
\end{tabular}

${ }^{\dagger}$ Estimated assuming nonporous spherical particles with a density corresponding to bulk anatase.

An equivalent set of materials was then prepared following a sol-gel route at $\mathrm{pH}$ 6.5. According to Wang and Ying [14], neutral aqueous media lead to anatase materials that undergo neither phase transition to rutile nor significant grain growth, whereas the use of nitric acid favours the formation of rutile. The XRD patterns (Figure 1) of these $\mathrm{pH} 6.5$ materials show that at both $500^{\circ} \mathrm{C}$ or $600^{\circ} \mathrm{C}$, pure anatase materials were obtained with only traces of rutile. Table 1 summarizes the composition calculated from the areas of the 101 anatase peak $\left(2 \theta \sim 25.3^{\circ}\right)$ and the 110 rutile peak $\left(2 \theta \sim 27.4^{\circ}\right)$ according to the procedure of Zhang and Banfield [15]:

$$
\text { Anatase }(\mathrm{wt} \%)=\frac{0.884 \times A_{\text {anatase }}}{0.884 \times A_{\text {anatase }}+A_{\text {rutile }}} \text {. }
$$

The average crystallite sizes were estimated from the width of signals using the Scherrer equation (Table 1). The average anatase size increased with calcination temperature, especially for materials synthesized at acidic $\mathrm{pH}$, which favours the thermal transformation to rutile.

\subsection{Photocatalytic results}

Figure 2 shows the photocatalytic activity of dispersions of these catalyst materials measured as the decrease with irradiation time of the absorption at $493 \mathrm{~nm}$. In all cases, a pseudofirst-order kinetics model satisfactorily represents the results and the derived first-order rate constants are shown in Table 1. In both cases, an increase in the temperature of the heat treatment from $500^{\circ} \mathrm{C}$ to $600^{\circ} \mathrm{C}$ leads to a significant increase in the activity even though the surface area, estimated from the average anatase size, decreases. However, the clear and important conclusion is that titania materials synthesized via the neutral sol-gel route are more photoactive than samples prepared in acid media.

The lack of correlation between photocatalytic activity and the specific surface area suggests that the reaction rate may be more influenced by the generally assumed higher activity of anatase. Although this would be consistent with the increased activity of $\mathrm{P}_{-} \mathrm{TiO}_{2}-4(100 \%$ anatase $)$ relative to $\mathrm{P}$ $\mathrm{TiO}_{2}-2$ (11\% rutile), it is inconsistent with the lower activity of $\mathrm{P}-\mathrm{TiO}_{2}-2$ relative to $\left(100 \%\right.$ anatase) $\mathrm{P}-\mathrm{TiO}_{2}-1$. We cannot exclude the possibility that since the $\mathrm{P}-\mathrm{TiO}_{2}-1$ was calcined at lower temperature, it may have significant amounts of amorphous $\mathrm{TiO}_{2}$, which reduces the photocatalytic activity.

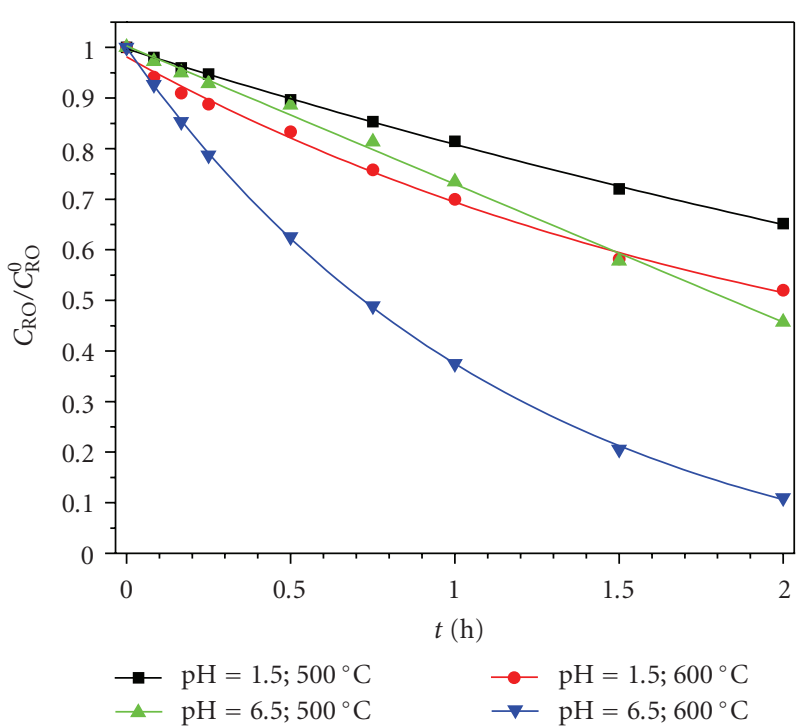

FIGURE 2: First-order kinetics fit of the RO16 photocatalytic decolorization.

\subsection{Photoelectrochemical results}

The striking increase in photocatalytic activity associated with the particle preparation at $\mathrm{pH} 6.5$ prompted a corresponding photoelectrochemical study on electrodes prepared by coating sol-gel $\mathrm{TiO}_{2}$ coated onto $1 \mathrm{~cm}^{2}$ titanium plates. Photocurrents were calculated as the difference between the current recorded in a cyclic voltammetry experiments in which the electrode was irradiated with UV light and the current recorded in the dark.

Figure 3(a) shows the influence of the $\mathrm{pH}$ on the photocurrent recorded in $0.1 \mathrm{M} \mathrm{Na}_{2} \mathrm{SO}_{4}$. As can be seen, the shape of the current voltage curve depended on the $\mathrm{pH}$ of the $\mathrm{TiO}_{2}$ coating suspension and on the treatment temperature. The curve for the electrode coated with a neutral $\mathrm{TiO}_{2}$ solution and heated at $500^{\circ} \mathrm{C}$ showed a progressive increase of the photocurrent with increase of the applied potential, in agreement with classical semiconductor theory. In contrast, for the electrode coated with an acidic $\mathrm{TiO}_{2}$ sol the photocurrent seems to be independent on the voltage. This previously observed [9] behaviour is attributed to particles, which are smaller than the thickness of the depletion layer. Because of this, increasing the electric field does not increase charge separation [16]. At higher temperatures, this effect disappears, 


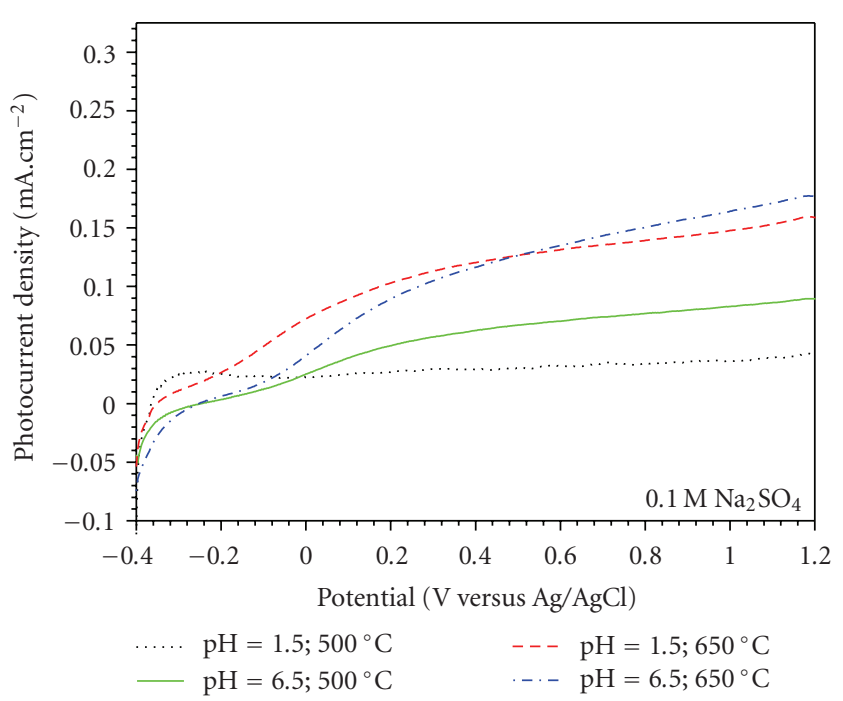

(a)

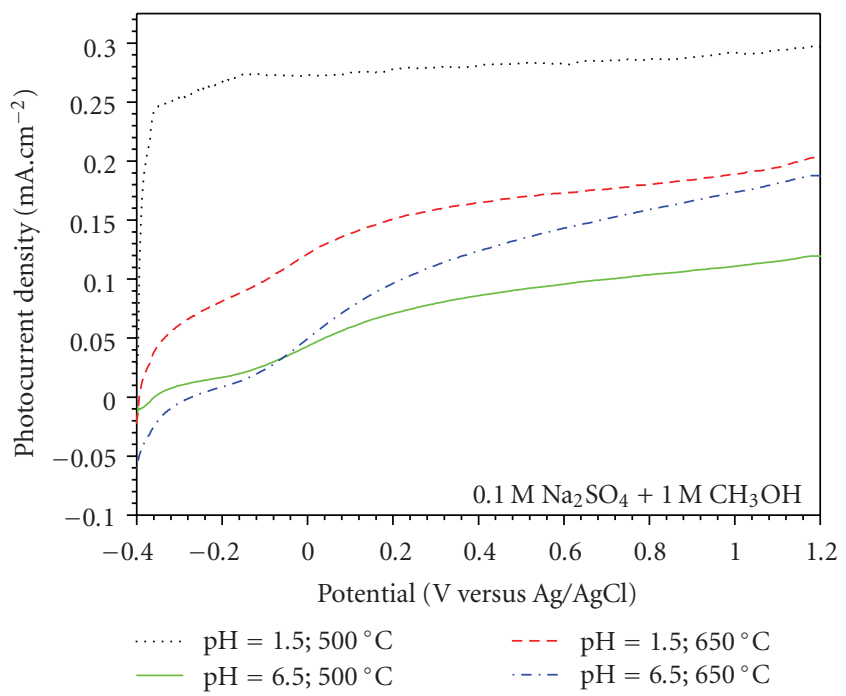

(b)

FIgURE 3: Influence of $\mathrm{pH}$ and temperature on the photocurrent density of $\mathrm{TiO}_{2}$ electrodes in (a) $0.1 \mathrm{M} \mathrm{Na}_{2} \mathrm{SO}_{4}$ and (b) $0.1 \mathrm{M}$ $\mathrm{Na}_{2} \mathrm{SO}_{4}+1 \mathrm{M} \mathrm{CH}_{3} \mathrm{OH}$.

probably by growing of the titania particles, and the cyclic voltammetries of both kind of electrodes are quite similar. In all cases, the photocurrents of neutral $\mathrm{TiO}_{2}$ electrodes at high potential values are higher than the photocurrent of acid $\mathrm{TiO}_{2}$ electrodes at high potentials.

Figure 3(b) also displays the corresponding current voltage curves after addition of $1 \mathrm{M}$ methanol to the electrolyte solution. Whereas the behaviour of the neutral $\mathrm{TiO}_{2}$ electrodes is quite similar to that in the absence of methanol, the photocurrents recorded for the acid $\mathrm{TiO}_{2}$ electrodes increase dramatically. This methanol enhancement has been previously reported by Christensen et al. [12] when comparing the photoelectrochemical properties of sol-gel electrodes (synthesized in acid media) with $\mathrm{TiO}_{2}$ electrodes obtained thermally from titanium plates. Similarly, Mintsouli et al.

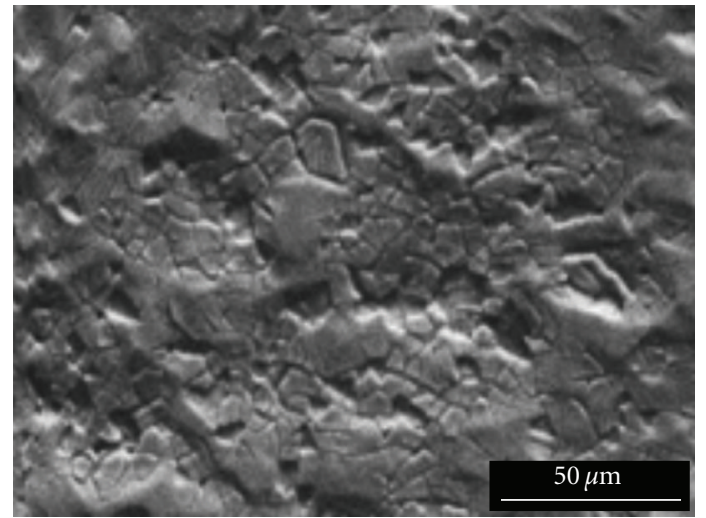

(a)

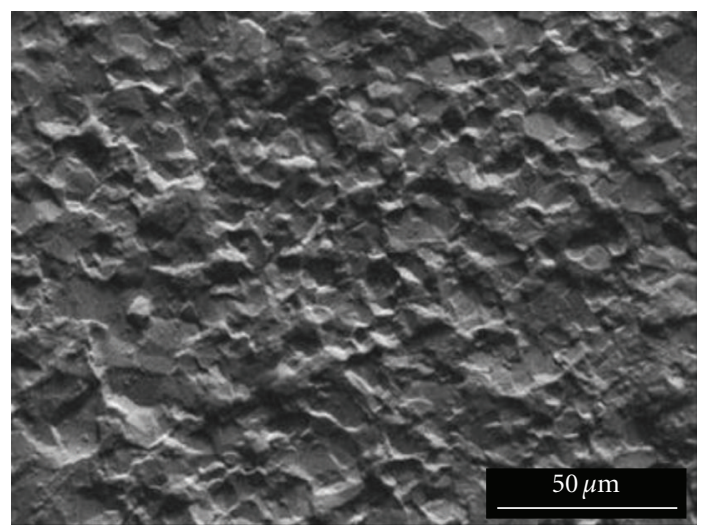

(b)

FIgURE 4: SEM micrographs spectra of $\mathrm{TiO}_{2}$ electrodes calcined at $500^{\circ} \mathrm{C}$ : (a) $\mathrm{pH}=1.5$ and (b) $\mathrm{pH}=6.5$.

[10] have reported a photocurrent enhancement in particulate electrodes (prepared from Degussa P25 suspensions) when adding oxalate to the electrolyte. In both cases, the organic compound is considered to scavenge photogenerated holes, decreasing charge recombination and hence increasing the photocurrent. This effect is reported to be especially marked in particulate electrodes of high roughness and titania surface area, but almost negligible for thermal electrodes [12]. The SEM micrographs, Figure 4, shows that the acid $\mathrm{TiO}_{2}$ electrode presents a more fractured but less rough surface, whereas the neutral $\mathrm{TiO}_{2}$ electrode calcined at $500^{\circ} \mathrm{C}$ consists of a continuous but rough film. At higher temperature, the two electrode types are more similar, although the neutral electrode seems to be more particulate.

Figures 5(a) and 5(b) show the influence of the heat treatment temperature on the photocurrent, measured at $1.0 \mathrm{~V}$, with and without the addition of methanol for the pH 1.5 and pH 6.5 electrodes. In $\mathrm{Na}_{2} \mathrm{SO}_{4}$ (only) solution, both electrodes show a maximum photocurrent at $650^{\circ} \mathrm{C}$ comparable with the maximum at $600-650^{\circ} \mathrm{C}$ reported by Christensen et al. [17]. For the pH 6.5 electrodes, the methanol photocurrent enhancement, calculated as the difference of the two plots, is vanishingly small for all heat treatment temperatures. For the $\mathrm{pH} 1.5$ electrodes, the methanol 


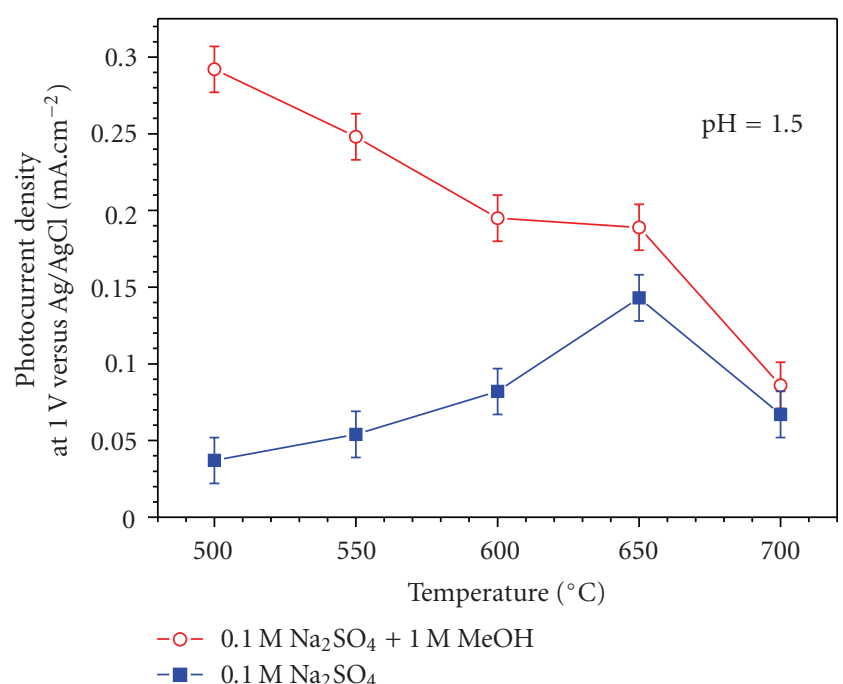

(a)

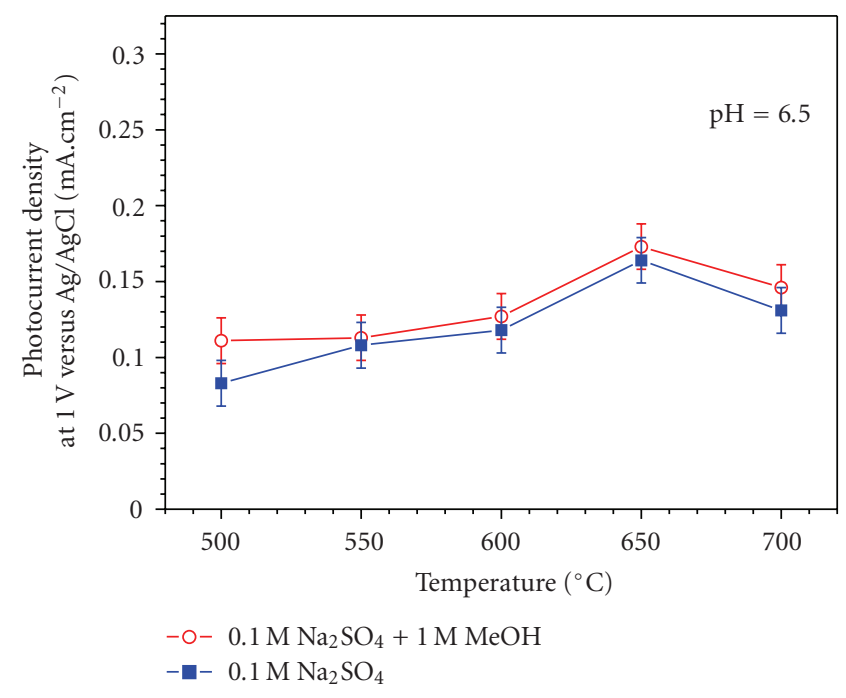

(b)

FIGURE 5: Influence of temperature on the photocurrent density of $\mathrm{TiO}_{2}$ electrodes: (a) $\mathrm{pH}=1.5$ and (b) $\mathrm{pH}=6.5$. The error bars have been estimated from the spread of 2 independent measurements.

photocurrent enhancement decreases to zero at $\sim 700^{\circ} \mathrm{C}$, which compares well with the $750^{\circ} \mathrm{C}$ reported in earlier work [17]. Consequently, the differences between electrodes synthesized in acid and neutral media disappear progressively when the calcination temperature is increased, probably due to the growth of the titania particles and the increase in the density of the titania film.

Figure 6 shows the X-ray diffraction patterns of the four electrodes. Acid sol-gel electrodes show the presence of anatase crystals at $500^{\circ} \mathrm{C}$. Narrowing of the diffraction lines confirms the crystallite growth between $500^{\circ} \mathrm{C}$ and $650^{\circ} \mathrm{C}$ (The crystal sizes calculated for the acid $\mathrm{pH}$ electrodes are 10.2, 23.0, 30.9, and $68.3 \mathrm{~nm}$ for calcination temperatures of $500,600,650$, and $700^{\circ} \mathrm{C}$, resp.). Although the anatase peak height is little altered, the integrated intensity has reduced suggesting that anatase has transformed to ru-

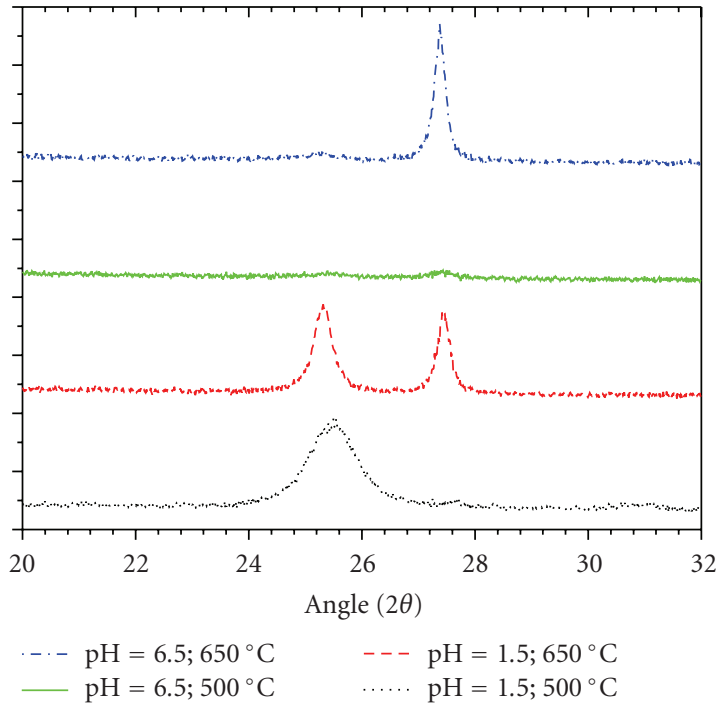

FIgURE 6: Influence of $\mathrm{pH}$ and temperature on the X-ray diffraction pattern of $\mathrm{TiO}_{2}$ small electrodes.

tile (A rutile phase is detected above $600^{\circ} \mathrm{C}$ ). Remarkably, no anatase phase was detected in neutral $\mathrm{pH} \mathrm{TiO}$ electrodes below a treatment temperature of $700^{\circ} \mathrm{C}$. However, rutile crystals were formed at lower temperatures, as was reported earlier for "thermal electrodes" prepared by heating titanium metal [17]. Therefore, these results suggest that either, unlike the $\mathrm{pH} 1.5$ coating, the crystal growth of the $\mathrm{pH} 6.5$ coating is controlled by the titanium substrate, or the rutile phase mainly grows directly from the oxidation of the titanium support.

Finally, the diffuse reflectance spectra of electrodes heated at $500^{\circ} \mathrm{C}$ are shown in Figure 7 . It is immediately obvious that these spectra are unlike the "typical" spectra of $\mathrm{TiO}_{2}$ and it is probable that they include a contribution from the underlying oxidized titanium metal. Separate studies [18] show that uncoated titanium metal is blue when heated to $500^{\circ} \mathrm{C}$ but grey or black when heated to $650^{\circ} \mathrm{C}$. The influence of the colored substrate is likely to be increased when the particle size of the sol-gel-derived $\mathrm{TiO}_{2}$ is small, and because it is not an efficient scatterer, it is not completely opaque. Despite these complications, the spectra show that for electrodes calcined at $500^{\circ} \mathrm{C}$ the peak absorption of the neutral $\mathrm{pH}$ electrode is $\sim 20 \mathrm{~nm}$ below that of the acid electrode whose peak is near $350 \mathrm{~nm}$. This blue shift could be explained by the extremely small crystallite size of the titanium dioxide particles (in agreement with the almost negligible intensity of the Xray diffraction signals). Small particles can cause the apparent absorption maximum to shift to shorter wavelengths - as described by Mie theory [19] — and may also lead to an increased band gap in quantum-size semiconductor particles [20].

At $650^{\circ} \mathrm{C}$, the increased absorption of the underlying oxidized titanium metal dominates the spectrum and its strong visible absorption means that the normally observed absorption edge is difficult to discern (therefore the $650^{\circ} \mathrm{C}$ spectra 


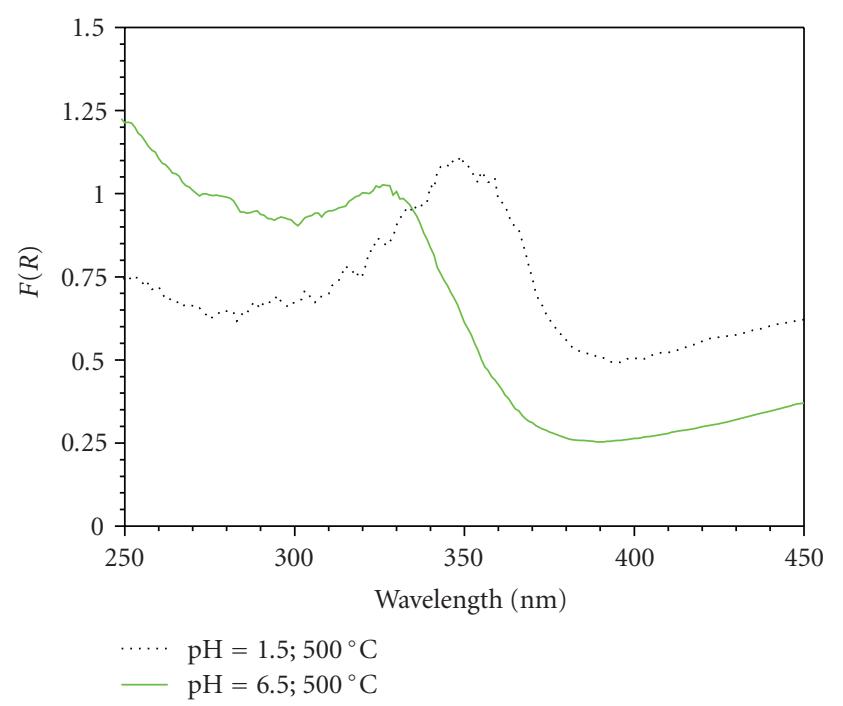

FIgURE 7: Influence of $\mathrm{pH}$ on the diffuse reflectance spectra of $\mathrm{TiO}_{2}$ electrodes.

are not reported). However, the difference between the neutral and acid electrodes appeared to have disappeared.

Summarising, the physicochemical characterization of the materials seems to point out that the use of a neutral solgel route leads to titania catalysts constituted by extremely small anatase crystals of higher activity in comparison with those obtained at acidic $\mathrm{pH}$ values. However, despite the strong dependence of the photoelectrochemical properties of the materials on the synthesis $\mathrm{pH}$, the photocurrents recorded under potentiostatic control do not correlate the activity exhibited by the materials for the decolorization of an azo dye solution.

\section{CONCLUSIONS}

The main conclusion of this work is the significance of the synthesis $\mathrm{pH}$ of sol-gel titania powders and electrodes for photocatalytic applications. In contrast with the large number of studies reporting the influence of the temperature on the physicochemical and photoelectrochemical properties of titania powders and coatings, our results indicate that $\mathrm{pH}$ is even more influential in controlling both the crystalline phases, and the photocatalytic activity of $\mathrm{TiO}_{2}$ powders and photocurrents of the electrodes. However, the photocatalytic activities of the $\mathrm{TiO}_{2}$ slurries are not proportional to the photocurrents recorded after immobilization on a conducting support. Consequently, these results indicate that the measurement of the photocurrent in an electrolyte media is not necessarily a good indicator of the photocatalytic activity of the unsupported system.

\section{ACKNOWLEDGMENTS}

Javier Marugán gratefully acknowledges the financial support of the Ministerio de Educación y Ciencia of Spain through the program Consolider-Ingenio 2010 (Project
CSD2006-00044 TRAGUA) and Comunidad de Madrid through the program REMTAVARES S-0505/AMB/0395.

\section{REFERENCES}

[1] D. F. Ollis and H. Al-Ekabi, Eds., Photocatalytic Purification and Treatment of Water and Air, Elsevier, Amsterdam, The Netherlands, 1993.

[2] M. R. Hoffmann, S. T. Martin, W. Choi, and D. W. Bahnemann, "Environmental applications of semiconductor photocatalysis," Chemical Reviews, vol. 95, no. 1, pp. 69-96, 1995.

[3] A. Mills and S. Le Hunte, "An overview of semiconductor photocatalysis," Journal of Photochemistry and Photobiology A, vol. 108, no. 1, pp. 1-35, 1997.

[4] J.-M. Herrmann, "Heterogeneous photocatalysis: fundamentals and applications to the removal of various types of aqueous pollutants," Catalysis Today, vol. 53, no. 1, pp. 115-129, 1999.

[5] A. Mills and S. K. Lee, "Semiconductor photocatalysis," in Advanced Oxidation Processes for Water and Wastewater Treatment, S. Parsons, Ed., IWA Publishing, London, UK, 2004.

[6] J. Marugán, D. Hufschmidt, G. Sagawe, V. Selzer, and D. Bahnemann, "Optical density and photonic efficiency of silicasupported $\mathrm{TiO}_{2}$ photocatalysts," Water Research, vol. 40, no. 4, pp. 833-839, 2006.

[7] L. Sun and J. R. Bolton, "Determination of the quantum yield for the photochemical generation of hydroxyl radicals in $\mathrm{TiO}_{2}$ suspensions," Journal of Physical Chemistry, vol. 100, no. 10, pp. 4127-4134, 1996.

[8] T. Egerton and P. Christensen, "Photoelectrocatalysis processes," in Advanced Oxidation Processes for Water and Wastewater Treatment, S. Parsons, Ed., IWA Publishing, London, UK, 2004.

[9] J. C. Harper, P. Christensen, T. Egerton, T. P. Curtis, and J. Gunlazuardi, "Effect of catalyst type on the kinetics of the photoelectrochemical disinfection of water inoculated with $E$. coli," Journal of Applied Electrochemistry, vol. 31, no. 6, pp. 623-628, 2001.

[10] I. Mintsouli, N. Philippidis, I. Poulios, and S. Sotiropoulos, "Photoelectrochemical characterisation of thermal and particulate titanium dioxide electrodes," Journal of Applied Electrochemistry, vol. 36, no. 4, pp. 463-474, 2006.

[11] J. Aguado, R. van Grieken, M.-J. López-Muñoz, and J. Marugán, "A comprehensive study of the synthesis, characterization and activity of $\mathrm{TiO}_{2}$ and mixed $\mathrm{TiO}_{2} / \mathrm{SiO}_{2}$ photocatalysts," Applied Catalysis A, vol. 312, no. 1-2, pp. 202-212, 2006.

[12] P. Christensen, T. P. Curtis, T. Egerton, S. A. M. Kosa, and J. R. Tinlin, "Photoelectrocatalytic and photocatalytic disinfection of E. coli suspensions by titanium dioxide," Applied Catalysis $B$, vol. 41, no. 4, pp. 371-386, 2003.

[13] B. O'Regan, J. Moser, M. Anderson, and M. Grätzel, "Vectorial electron injection into transparent semiconductor membranes and electric field effects on the dynamics of lightinduced charge separation," Journal of Physical Chemistry, vol. 94, no. 24, pp. 8720-8726, 1990.

[14] C.-C. Wang and J. Y. Ying, "Sol-gel synthesis and hydrothermal processing of anatase and rutile titania nanocrystals," Chemistry of Materials, vol. 11, no. 11, pp. 3113-3120, 1999.

[15] H. Zhang and J. F. Banfield, "Understanding polymorphic phase transformation behaviour during growth of nanocrystalline aggregates: insights from $\mathrm{TiO}_{2}$," Journal of Physical Chemistry B, vol. 104, no. 15, pp. 3481-3487, 2000. 
[16] K. Vinodgopal, U. Stafford, K. A. Gray, and P. V. Kamat, "Electrochemically assisted photocatalysis. 2. The role of oxygen and reaction intermediates in the degradation of 4chlorophenol on immobilized $\mathrm{TiO}_{2}$ particulate films," Journal of Physical Chemistry, vol. 98, no. 27, pp. 6797-6803, 1994.

[17] P. Christensen, T. Egerton, S. A. M. Kosa, J. R. Tinlin, and K. Scott, "The photoelectrocatalytic oxidation of aqueous nitrophenol using a novel reactor," Journal of Applied Electrochemistry, vol. 35, no. 7-8, pp. 683-692, 2005.

[18] J. R. Tinlin, "Photoelectrocatalysis by $\mathrm{TiO}_{2}$ electrodes," University of Newcastle upon Tyne, Newcastle upon Tyne, UK, 2002.

[19] C. F. Bohren and D. R. Huffman, Absorption and Scattering of Light by Small Particles, John Wiley \& Sons, New York, NY, USA, 1983.

[20] Z. Zhang, C. C. Wang, R. Zakaria, and J. Y. Ying, "Role of particle size in nanocrystalline $\mathrm{TiO}_{2}$-based photocatalysts," Journal of Physical Chemistry B, vol. 102, no. 52, pp. 10871-10878, 1998. 


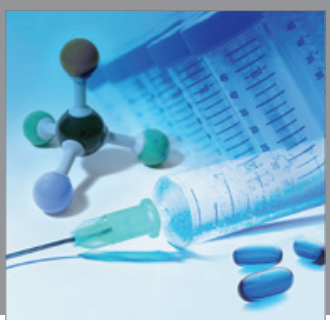

International Journal of

Medicinal Chemistry

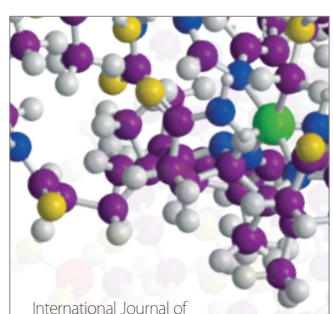

Carbohydrate Chemistry

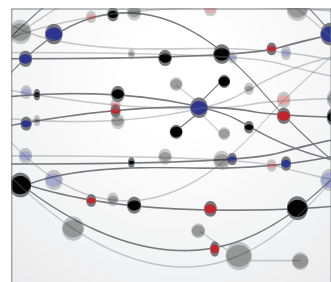

The Scientific World Journal
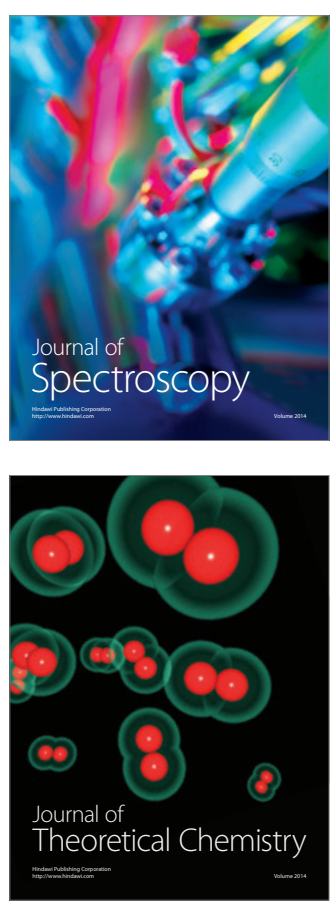
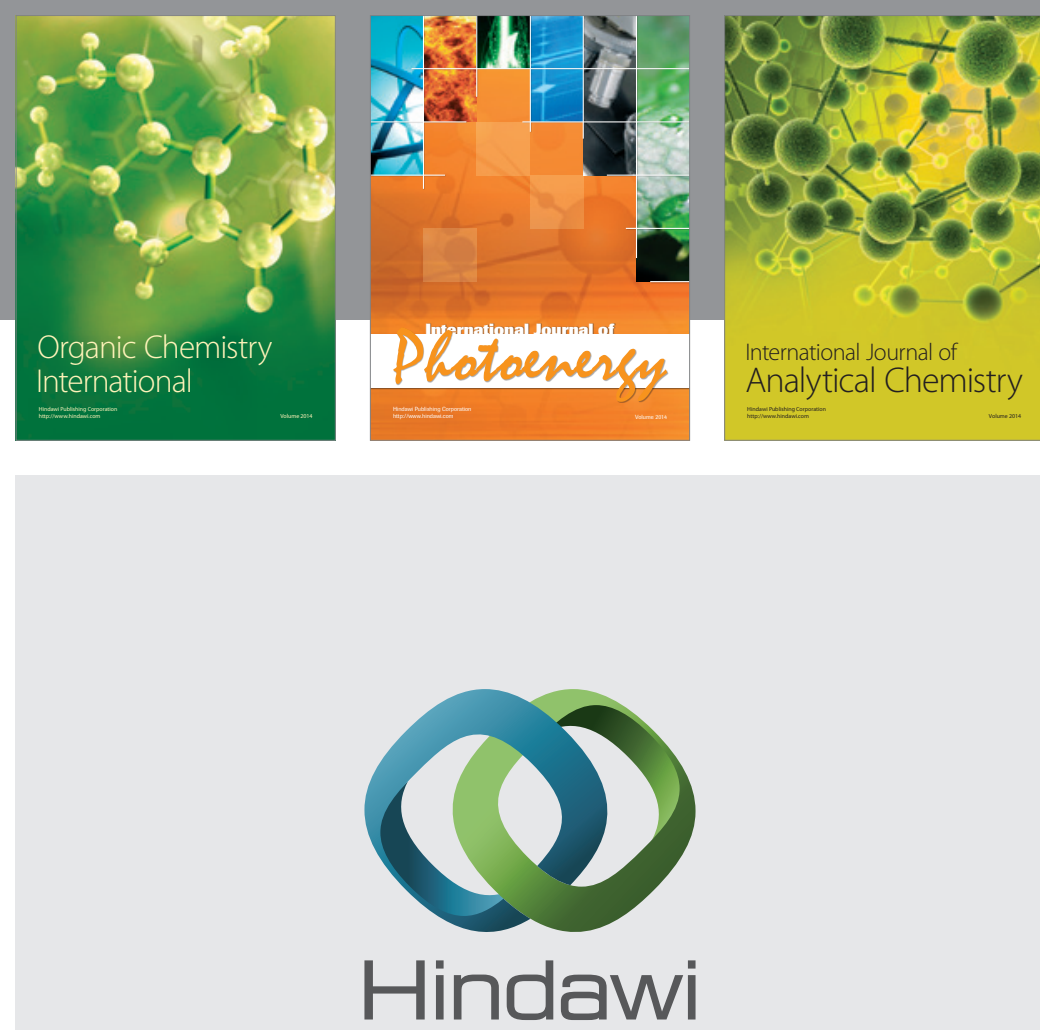

Submit your manuscripts at

http://www.hindawi.com
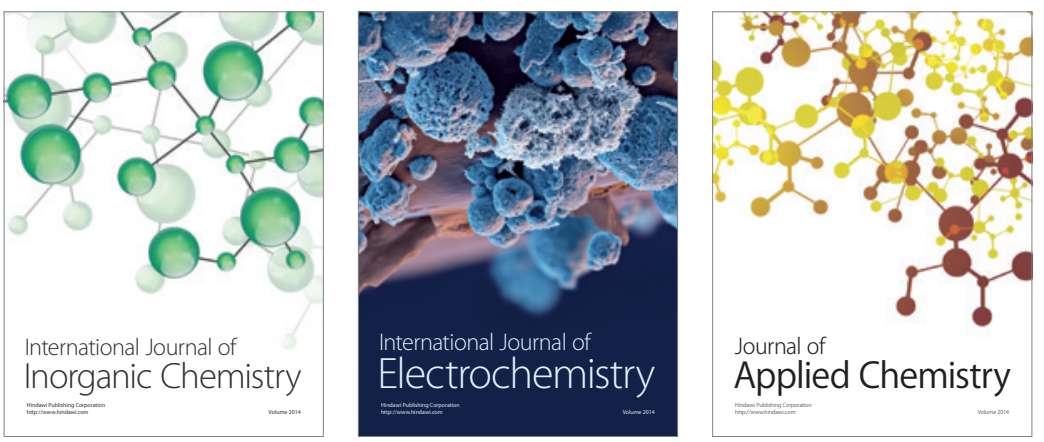

Journal of

Applied Chemistry
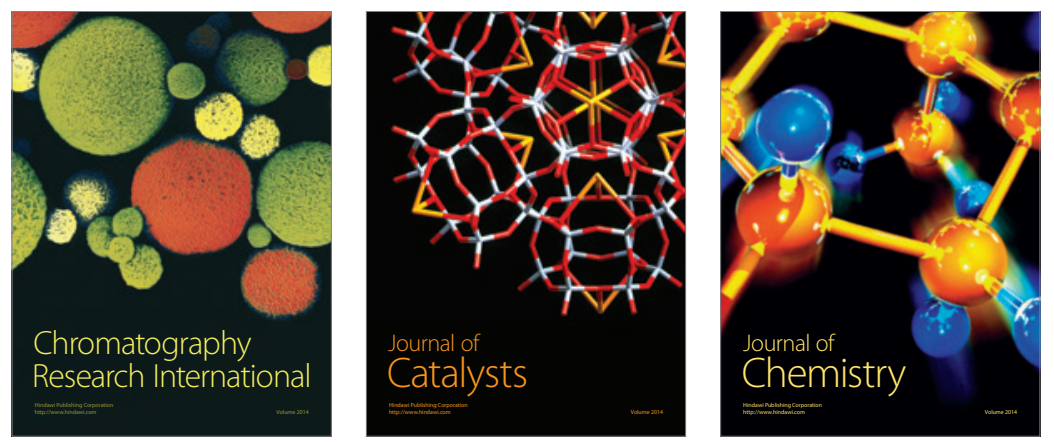
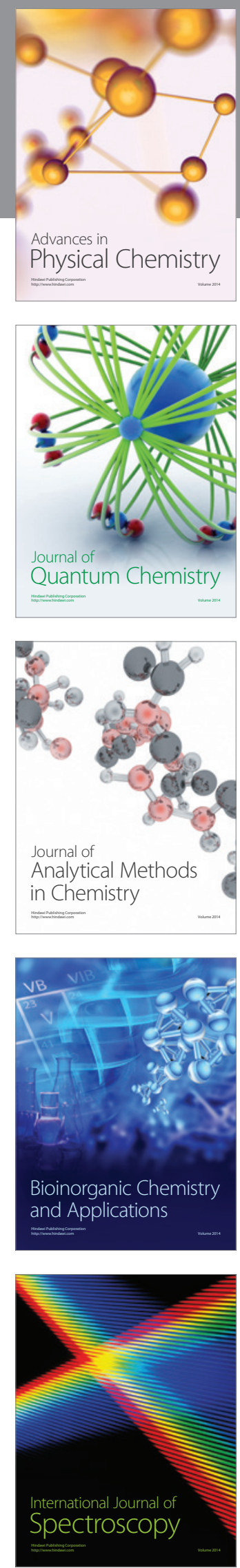